\title{
COMPETITIVE ADVANTAGES AND COMPANY'S PERFORMANCE: ANALYZING THE RELATIONSHIP
}

\author{
Pisit Potjanajaruwit
}

Suan Sunandha Rajabhat University, Bangkok, Thailand

This research on the competitive advantages' effects on firm performance had the primary objective to examine the causal factors of competitive advantage that influence the performance of startups in Thailand. This research employed mixed methods that encompassed conducting both qualitative and quantitative research and analyzing data through the use of structural equation modeling (SEM). From the obtained results, it becomes evident that: technological capability (TNCB) had a positive direct influence on competitive advantage (CPAD) with the effect size of 0.34 ; interorganizational collaboration (IOCB) had a positive direct influence on competitive advantage (CPAD) with the effect size of 0.22; and competitive advantage (CPAD) had a positive direct influence on startup firm performance (STUFP) with the effect size of 0.22, at the significance level of 0.01 .

Keywords: competitive advantage; technological capability; interorganizational collaboration; startups; firm performance.

\section{Introduction}

Competitive advantage is regarded as one of the most crucial elements in operating a business. Without development or incorporation of new technologies and innovations, it is certainly difficult for an organization to become successful in the long run. Indeed, organizational success generally stems from the adoption of innovations, whether in the aspect of products, operational process, services, management, or marketing. Innovative enterprises tend to adopt new management concepts that encompass changes in organizational characteristics or behaviors to respond to stimuli in the context of globalization, where knowledge and innovation are the key to value addition (Jones, 2003). Furthermore, innovation does not only play a significant role in the development of products and services to fulfill the needs of consumers, but it also facilitates organizations' survival at a particular market and their acquisition of competitive advantages under the conditions of free market. For businesses in Thailand to develop into truly innovative businesses, the executives must be committed to promoting and implementing innovations. Highly innovative businesses are typically

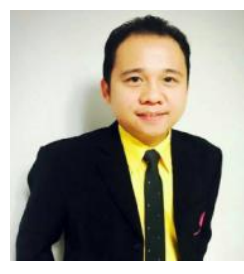

\section{Pisit Potjanajaruwit}

Doctor of Business Administration (Marketing) in Sripatum University, Bangkok, Thailand Assistant Dean for International Affairs, Faculty of Management Science,

Suan Sunandha Rajabhat University, Thailand

Research interests: integrated marketing communication, branding strategy, service marketing for Sufficiency Economy

E-mail: pisit.po@ssru.ac.th 


\section{COMPETITIVE ADVANTAGES AND COMPANY'S}

characterized by the following features: leadership, planning, information, people, processes, and results.

In addition, implementation of innovations entails the assessment of organizational performance so that to identify the degree of success with respect to the predetermined goal or target, as well as to evaluate operational efficiency and determine strengths, weaknesses, and opportunities in relation to further development. Likewise, performance assessment enables organizations recognize very different factors, including the need for growth and market development.

Understanding of organizational capability facilitates organizations to undergo development in various aspects for the purposes of survival and operational stability. As of today, there are various criteria for performance assessment. Although some criteria emphasize solely on the financial dimension, this research aims to assess organizational performance in a broader sense, by means of applying one of the most widely used concepts and approaches to performance assessment - the balanced scoreboard (BSC) approach.

This approach serves as a tool for measuring and evaluating organizational performance in four aspects, consisting of: financial perspective, customer perspective, internal process perspective, and learning and growth perspective (Kaplan, 1996). Nevertheless, regardless of how promising a product or a marketing plan is, the weaknesses of an organization will impede it from utilizing the stipulated strategies to obtain optimal benefits. On the other hand, an organization that continually develops and implements innovations to acquire a competitive advantage will undoubtedly enjoy sustainable growth. With that in mind, a study on innovative enterprises is crucial since it may allow organizations receive the maximum possible benefits. It is evident that previous studies on innovations have examined mostly the degree of innovativeness of organizations, which was evaluated by external agencies. Moreover, these studies did not analyze the outcomes of being an innovative enterprise, nor did they examine the relationships or effects from innovations on organizational performance.

According to the aforementioned reasons, the researcher here was intrigued to study the effects of competitive advantage on the performance of startups in Thailand in order to identify the strengths and weaknesses of Thai enterprises. Furthermore, concerning the differences in the nature of competitive advantage between business and industry, the researcher intended to determine the features of competitive advantage that are adherent for startups in Thailand. Hence, this research aims to study the effects of competitive advantage on the performance of startups in Thailand.

Our research objective is to examine the causal factors behind competitive advantage that influence the performance of startups in Thailand.

\section{Research Hypotheses}

Hypothesis 1: Technological capability has direct influence on the competitive advantage of startups in Thailand.

Hypothesis 2: Interorganizational collaboration has direct influence on the competitive advantage of startups in Thailand.

Hypothesis 3: Competitive advantage has direct influence on the performance of startups in Thailand.

Hypothesis 4: Technological capability has direct influence on the performance of startups in Thailand. 
Hypothesis 5: Interorganizational collaboration has direct influence on startup firms' performance in Thailand.

\section{Literature Review}

\section{Competitive Advantage}

M. Porter (1980) defined the three strategies using which literary any organization can achieve competitive advantage over its competitors: cost leadership strategy, differentiation strategy, and focus group strategy. These strategies include but are not limited to providing high-quality products and services to consumers at a lower cost than that of the competitors and acquiring advantage in terms of geographic location. Alternatively, Gassmann and Keupp (2007) defined competitive advantage as the ability of an organization that is derived from valuable resources, such as the ability to create innovation with high efficiency and the ability to differentiate itself from other market players. Competitive advantage enables an organization to compete with its competitors, while maintaining its customer base. Essentially, there are various approaches to acquiring competitive advantage, such as providing high-quality products, offering excellent services, achieving cost advantage and location-specific advantage, and branding - all of which have the ultimate goal to ensure that customers will receive value for money. In creating competitive advantage, organizations must provide whatever is best for customers. Meanwhile, in the perspectives of customers, they seek for products or services that are worth the money spent, whether in the aspect of quality or price.

There are three main principles of competitive advantage:

1) Cost leadership, which was widely adopted in the 1970s under the belief that costs would be lower if the personnel had expertise and experience in that field. Hence, the cost leadership strategy predominantly relies on the accumulated experience to reduce both manufacturing and operating costs.

2) Differentiation, which is a strategy that involves differentiating products and services from those of the competitors. The implementation of this strategy will strengthen organizations against Porter's Five Forces, while allowing them to establish customer loyalty. In the presence of loyalty, customers will become less sensitive to price, which subsequently enables organizations to compete with other market players in an efficient and effective manner, as well as increasing the barriers to entry.

3) Focus group, which is a strategy that focuses on a specific target group, whether in terms of demography or geographic location. In other words, organizations that employ this strategy will aim to satisfy the needs of a specific group of customers rather than general customers.

With that respect, it is significant for an organization to offer products or services that are unique and distinct from those of its competitors through an emphasis on cost reduction or product differentiation, or both, in order to cater to the needs of a specific target group. Thus, this strategy is different from the cost leadership strategy that emphasizes on fulfilling the needs of all groups of customers (Wingwon, 2012).

Accordingly, the researcher has divided the concept of competitive advantage into three primary components, which can be summarized as follows:

1. Cost advantage - organizations will focus on providing products and services at a lower cost than those of the competitors, while maintaining the quality of their products and 


\section{COMPETITIVE ADVANTAGES AND COMPANY'S}

services at a level acceptable by the market, in order to increase profits and expand into new market segments.

2. Differentiation advantage - organizations will emphasize on creating products and services that are unique and distinct from those of competitors, whether in the aspect of technology, production process, product quality, or logistics, whereby these products and services must exceed customers' expectations.

3. Market focus advantage - organizations will focus on penetrating into a specific market by contemplating their expertise and accessibility to that market, as well as the growth potential of that market.

4. Differentiation is the provision of products and services that are distinct from those of the competitors, whether by means of providing value for money or using a production process that adds value to the products and services in order to maximize customer satisfaction. Differentiation can be achieved by various methods, such as creating brand image, developing quality, implementing the principles of total quality management, building brand equity etc.

5. Cost advantage is the production of products and services at lower costs as compared to competitors. This advantage enables organizations to offer their products and services at lower prices, while increasing their market share and profitability.

6. Focus advantage involves utilizing the acquired cost advantage or differentiation by focusing on a specific group of customers or a certain niche market.

7. New market entry enables organizations to gain competitive advantage through the use of resources and capability as a result of being the first mover and/or a pioneer in a particular technology.

8. Synergy is the collaboration between two or more organizations so that to produce a combined effect that is greater than the sum of their separate effects. This subsequently results in value addition, cost reduction, and higher performance as compared to competitors.

\section{Research Methodology}

This research on the effects of competitive advantage on the performance of startups in Thailand is a mixed methods research; it employs qualitative research in conjunction with quantitative research (Creswell, 2009).

This research was conducted in three parts. First, a qualitative research was conducted on the executives of startups in Thailand, including the owners of SMEs involved in creating competitive advantage for their businesses. Data collection was done through the use of indepth interviews. Secondly, a quantitative research in the form of a survey was conducted by means of questionnaires. Contents and structure of the questionnaires were designed on the basis of the results derived from the qualitative research (the first part).

The results obtained from the survey were used to identify the causal factors that have an influence on the competitive advantage of startups in Thailand.

Third, structural equation modeling was employed to analyze the causal relationship between the factors influencing the competitive advantage of startups in Thailand. In addition, the researcher examined the related theories and the literature to develop a conceptual framework for own research model. The fitness of the research model with respect to the empirical data was assessed using LISREL 8.80 for Windows, with the fit indices consisting of: normalized chi-square $(\chi 2 / \mathrm{df})$, comparative fit index (CFI), goodness of fit index (GFI), 
adjusted goodness of fit index (AGFI), root mean square error of approximation (RMSEA), and standardized root mean square residual (SRMR).

\section{Results}

According to the analysis of the causal factors of competitive advantage that influence the performance of startups in Thailand based on the variables in the causal model of competitive advantage that affect the performance of startups in Thailand (direct effect, indirect effect, and total effect), the results indicated that such model was consistent with the empirical data.

According to the foregoing results, the researcher was able to propose the research findings so that to answer the question of "whether technological capability and interorganizational collaboration have influence on the competitive advantage of startups in Thailand and how exactly". The researcher had formulated five hypotheses in order to answer the above research question, as follows:

Hypothesis 1: Technological capability has direct influence on the competitive advantage of startups in Thailand. The results of this hypothesis testing indicated that technological capability (TNCB) had a positive direct influence on competitive advantage (CPAD) at the significance level of 0.01 , whereby the total effect of TNCB on CPAD was 0.34 - all of which were direct effect.

Hypothesis 2: Interorganizational collaboration has direct influence on the competitive advantage of startups in Thailand. The results of hypothesis testing indicated that interorganizational collaboration (IOCB) had a positive direct influence on competitive advantage (CPAD) at the significance level of 0.01 , whereby the total effect of IOCB on CPAD was 0.22 - all of which were direct effect.

Hypothesis 3: Competitive advantage has a direct influence on startup firms' performance. The results of this hypothesis testing indicated that competitive advantage (CPAD) had a positive direct influence on startup firms' performance (STUFP) at the significance level of 0.01 , whereby the total effect of CPAD on STUFP was 0.22 - all of which were direct effects.

Hypothesis 4: Technological capability has a direct influence on startup firm performance. The results of hypothesis testing indicated that technological capability (TNCB) had a positive direct influence on startup firm performance (STUFP) at the significance level of 0.01 , whereby the total effect of TNCB on STUFP was 0.25 , consisting of direct effect and indirect effect at 0.17 and 0.07 , respectively.

Hypothesis 5: Interorganizational collaboration has direct influence on startup firms' performance. The results of hypothesis testing indicated that interorganizational collaboration (IOCB) had a positive direct influence on startup firms' performance (STUFP) at the significance level of 0.01 , whereby the total effect of IOCB on STUFP was 0.47 , consisting of direct effect and indirect effect at 0.42 and 0.05 , respectively.

Accordingly, the results of hypotheses' testing concerning the causal factors of competitive advantage that influence the performance of startups in Thailand can be concluded as follows: 


\section{COMPETITIVE ADVANTAGES AND COMPANY'S}

\begin{tabular}{|c|l|c|}
\hline$\#$ & \multicolumn{1}{|c|}{ Hypotheses } & \multicolumn{1}{|c|}{ Outcome } \\
\hline 1 & $\begin{array}{l}\text { Technological capability has a direct influence on the } \\
\text { competitive advantage of startups in Thailand. }\end{array}$ & Hypothesis accepted \\
\hline 2 & $\begin{array}{l}\text { Interorganizational collaboration has a direct influence } \\
\text { on the competitive advantage of startups in Thailand. }\end{array}$ & Hypothesis accepted \\
\hline 3 & $\begin{array}{l}\text { Competitive advantage has a direct influence on } \\
\text { startup firm performance. }\end{array}$ & $\begin{array}{l}\text { Hypothesis accepted } \\
\text { startup firm performance. }\end{array}$ \\
\hline 5 & $\begin{array}{l}\text { Interorganizational collaboration has a direct influence } \\
\text { on startup firm performance. }\end{array}$ & Hypothesis accepted \\
\hline
\end{tabular}

\section{Conclusion}

After considering the model fit indices, it was found that the model conformed to the empirical data, whereby all six indices passed the acceptance criteria: $\chi^{2} / \mathrm{df}=1.07, \mathrm{CFI}=1.00$, $\mathrm{GFI}=1.00, \mathrm{AGFI}=0.99, \mathrm{RMSEA}=0.013$, and $\mathrm{SRMR}=0.026$. Hence, it was concluded that the structural equation model was appropriate and in harmony with the empirical data, which could be explained as follows: 1$)$ the normalized chi-square $\left(\chi^{2} / \mathrm{df}\right)$ was equal to 1.07 , which implied that the model was in harmony with the empirical data, since the value was lower than $2.00 ; 2)$ the comparative fit index (CFI) was equal to 1.00 , which implied that the model was in harmony with the empirical data, since the value was greater than $0.95 ; 3$ ) the absolute fit index was measured on the basis of two indices, comprising the goodness of fit index (GFI) with the value of 1.00 and the adjusted goodness of fit index (AGFI) with the value of 0.99, which indicated that the model was in harmony with the empirical data, since the values of GFI and AGFI were greater than 0.95 and 0.90 , respectively; 4) the root mean square error of approximation (RMSEA) was equal to 0.013 , which implied that the model was in harmony with the empirical data, since the value was lower than 0.05; and 5) the standardized root mean square residual (SRMR) was equal to 0.026, which indicated that the model was in harmony with the empirical data, since the value was lower than 0.05 .

These results are consistent with the research of O'Donnell, Gilmore, Carson, and Cummins (2002), who also found that technological capability and interorganizational collaboration were the key factors for SMEs and startups while achieving competitive advantage. Furthermore, according to the literature review, it is apparent that technological capability and interorganizational collaboration do not solely depend on the availability of resources in the aspect of computers or machinery. Rather, one of the most important elements concerning technological capability and interorganizational collaboration is the ability of personnel to learn and apply their knowledge so that to add economic value to their organization. In conclusion, the measurement of technological capability can be modified to the fact that this concept is appropriate for researches on real estate businesses and its national context as well. 
On a final note, since startup businesses are typically small and rather informal organizational structures, the use of subjective measurements in relation to them would be more appropriate. Subjective measurement of technological capability can be performed by dividing the components into the aspects of acceptance and implementation in order to elucidate research findings in a more explicit and detailed manner. This can be one of the potential promising directions for further research in the same direction.

\section{References:}

Creswell, J. W. (2009). Mapping the Field of Mixed Methods Research. Journal of Mixed Methods Research, Vol 3, Issue 2, pp. 95-108, https://doi.org/10.1177/1558689808330883

Gassmann, O., \& Keupp, M. M. (2007). The Competitive Advantage of Early and Rapidly Internationalizing SMEs in the Biotechnology Industry: A Knowledge-Based View. Journal of World Business, 42(3). Pp. 350-366.

Jones, O. (2003). Competitive Advantage in SMEs: Towards a Conceptual Framework. Competitive Advantage in SMEs: Organizing for Innovation and Change. Pp. 15-33.

Kaplan, R. S., \& Norton, D. P. (1996). The Balanced Scorecard: Translating Strategy into Action. Harvard Business Press.

O’Donnell, A., Gilmore, A., Carson, D., \& Cummins, D. (2002). Competitive Advantage in Small to Medium-Sized Enterprises. Journal of Strategic Marketing, 10(3). Pp. 205-223.

Porter's (1980) Generic Strategies as Determinants of Strategic Group Membership and Organizational Performance. Academy of Management Journal, 27(3). Pp. 467-488.

Wingwon, B. (2012). Effects of Entrepreneurship, Organization Capability, Strategic Decision Making and Innovation Toward the Competitive Advantage of SMEs Enterprises. Journal of Management and Sustainability, 2(1). Pp. 137.

Paper submitted

Paper accepted for publishing

Paper published online
17 January 2018

21 March 2018

15 June 2018 